\title{
ROTATIVIDADE MIGRATÓRIA: UM NOVO OLHAR PARA AS MIGRAÇÕES INTERNAS NO BRASIL
}

\author{
Rosana Baeninger*
}

\begin{abstract}
O artigo analisa os movimentos migratórios no Brasil, acompanhando as transformações em sua dinâmica nas últimas décadas. Os movimentos migratórios internos no Brasil, dos últimos 60 anos, estão fortemente relacionados aos processos de urbanização e de redistribuição espacial da população, marcados pela intensa mobilidade populacional. Nesse contexto, os clássicos fatores de atração e expulsão se esgotam para as explicações do fenômeno migratório. As evidências empíricas dos censos demográficos e das PNADs permitem conhecer as alterações nas tendências migratórias nacionais, revelando novas condições migratórias para diferentes estados: áreas de retenção migratória, áreas de perdas migratórias e áreas de rotatividade migratória. O século 21 anuncia a expansão dos espaços da migração no Brasil, marcados pelo crescimento de áreas de rotatividade migratória.
\end{abstract}

Palavras-chave: Migração interna; Ubanização; Migração interestadual.

\section{Introdução}

O tema das migrações internas no Brasil adquire importância crescente nos estudos de população no século 21. De um lado, as migrações de longa distância redesenharam seus trajetos e seus significados; de outro lado, as dinâmicas regionais passaram a imprimir especificidades às migrações urbanas-urbanas.

O artigo analisa os movimentos migratórios no Brasil, acompanhando as transformações em sua dinâmica nas últimas décadas. Os movimentos migratórios internos no Brasil, dos últimos 60 anos, estão fortemente

* Doutora em Ciências Sociais, professora colaboradora do Departamento de Demografia do Instituto de Filosofia e Ciências Humanas da Unicamp, Pesquisadora do Núcleo de Estudos de População da Unicamp. E-mail: baeninger@reitoria.unicamp.br. Campinas/Brasil. 
relacionados aos processos de urbanização e de redistribuição espacial da população, marcados pela intensa mobilidade populacional, e inseridos nas distintas etapas econômicas, sociais e políticas experimentadas pelo país ao longo desse período.

Desse modo, o deslanchar dos processos migratórios recentes tem suas raízes de transformações desde os anos 1980, quando as clássicas interpretações da migração ancorada somente no desempenho econômico das áreas alcançaram seus limites. O artigo recapitula as tendências gerais da migração nos anos 1980 e 1990 no Brasil, a fim de que se possa acompanhar, no longo prazo, a manifestação das migrações internas no país e sua configuração atual. Focaliza no século 21, os processos migratórios nacionais que, imersos em um novo contexto socioeconômico e urbano, imprimem espaços da migração marcados por diferentes "condição migratória": áreas de retenção de população, áreas de perdas migratórias e áreas de rotatividade migratória.

As análises relativas aos primeiros anos do século 21 comparam as informações sobre os movimentos migratórios para todos os Estados brasileiros, no período 1995-2000 e 2005-2010, com base no Censo Demográfico de 2000 e 2010; para os períodos intercensitários de 1999-2004, 2001-2006, 2003-2008 e 2004-2009 nas Pesquisas Nacionais por Amostra Domiciliar. Busca-se apresentar os movimentos migratórios contemporâneos, em particular aqueles referentes aos últimos anos, que imersos em um novo contexto socioeconômico e urbano, imprimem espaços da migração marcados por diferentes "condição migratória": áreas de retenção de população, áreas de perdas migratórias e áreas de rotatividade migratória.

Nesse contexto, apresenta-se a seguir algumas reflexões que contemplam o cenário recente das migrações internas no Brasil, com a incorporação do conceito de rotatividade migratória para o entendimento teórico-metodológico dos processos migratórios em curso no país.

\section{Breve retrospectiva}

Os movimentos migratórios internos no Brasil, dos últimos 60 anos, estão fortemente relacionados aos processos de urbanização e de redistribuição espacial da população, marcados pela intensa mobilidade populacional, e inseridos nas distintas etapas econômicas, sociais e políticas experimentadas pelo país ao longo desse período.

As mudanças no processo migratório nacional tiveram, a partir dos anos 70, o deslanchar de suas transformações. No contexto dos deslocamentos interestaduais apesar da centralidade migratória no Sudeste - São Paulo e Rio 
de Janeiro foram os dois Estados dessa Região que já haviam assistido a uma redução em seus volumes de imigrantes dos anos 70 para os $80 .{ }^{1}$ O Sudeste que chegava a ter um movimento migratório que envolvia quase 5 milhões de pessoas nos anos 70, diminuiu este volume para 4,3 milhões no período 1981-1991.

Na Região Centro-Oeste, os Estados do Mato Grosso do Sul e do Distrito Federal também diminuíram seus volumes de imigrantes entre esses dois períodos. O Mato Grosso do Sul demonstrava sinais do "fechamento de sua fronteira" ${ }^{2}$ e o Distrito Federal iniciava, no período 1981-1991, seu processo de expansão metropolitana atingindo os municípios do Estado de Goiás, com significativos fluxos migratórios para seu entorno.

Ao longo dos últimos cinquenta anos do século 20, as migrações internas reorganizaram a população no território nacional, onde as vertentes da industrialização e das fronteiras agrícolas constituíram os eixos da dinâmica da distribuição espacial da população no âmbito interestadual, muito embora a primeira vertente detivesse os fluxos mais volumosos. Nesse sentido, as análises a respeito do processo de distribuição espacial da população nos anos 70, e até mesmo durante a década de 80, estiveram baseadas e preocupadas em apontar o crescente e intenso movimento de concentração: da migração, com a predominância do fluxo para o Sudeste; do processo de urbanização, com a enorme transferência de população do campo para a cidade, quando cerca de 15,6 milhões deixaram as áreas rurais nesse período; ${ }^{3}$ e, a concentração da população, manifestada no processo de metropolização.

De fato, essas características representaram e compuseram a sociedade urbano-industrial brasileira, ${ }^{4}$ com a concentração tanto de atividades econômicas quanto populacional. É revelador nesse processo, no entanto, que os efeitos da desconcentração relativa das atividades econômicas, ${ }^{5}$ iniciados no decorrer dos anos 70, não tivesse tido reflexos imediatos nos deslocamentos populacionais captados pelo censo demográfico de 1980; somente no período 1981-1991 é que esse processo tornou-se mais evidente,

1 BAENINGER, Rosana. Região, Metrópole e Interior: espaços ganhadores e espaços perdedores nas migrações internas no Brasil, 1980-1996.

2 MARTINE, George. "A redistribuição espacial da população brasileira durante a década de 80", IDEM. "Migração e metropolização".

Ibidem.

4 FARIA, Vilmar. "Cinquenta anos de urbanização no Brasil: tendências e perspectivas".

5 Cf. NEGRI, Barjas. Concentração e desconcentração industrial em São Paulo (1880-1990); DINIZ, Célio C. "Dinâmica regional recente e suas perspectivas"; CANO, Wilson. "Novas Determinações sobre a Questão Regional e Urbana após 1980"; PACHECO, Carlos Américo. Fragmentação da nação. 
sugerindo uma defasagem entre os deslocamentos das atividades econômicas e os deslocamentos de população. ${ }^{6}$

No entanto, além das "trajetórias dominantes"7, fenômenos de suma importância para a dinâmica da mobilidade espacial da população já emergiam naquele período. Um deles referia-se ao refluxo de mineiros para seu Estado já nos anos $70,{ }^{8}$ apontando o incipiente processo de reversão emigratória da área; cerca de 35,6\% dos imigrantes para o Estado de Minas Gerais eram de retorno naquele período. O processo de desconcentração das atividades econômicas que marcava o período 1970-1980 beneficiou Minas Gerais, podendo já ter contribuído, nesse período, para a absorção de sua população natural, bem como para atração e, inclusive, refluxo de população.

Outro aspecto a considerar refere-se aos possíveis destinos migratórios nos anos 70. Martine y Carvalho ${ }^{9}$ sintetizam os deslocamentos populacionais, desse período, destacando a ocorrência do aumento no número de Estados expulsores de população e a redução nos receptores. Na verdade, das vinte e seis UF's existentes em 1980, ${ }^{10}$ onze delas haviam registrado trocas migratórias positivas com outros Estados, das quais cinco estavam no Norte, indicando que entre 1970-1980 essa fronteira foi capaz de aumentar o número de Estados absorvedores de população no País; no cômputo geral, havia, nos anos 70, mais Estados "perdedores" que "ganhadores" de população. ${ }^{11}$ Essa situação inverteu-se na década seguinte, com os anos 80 entrando na história migratória recente do País com o maior número de "espaços ganhadores" nas migrações interestaduais, mesmo tendo o Rio de Janeiro registrado perdas populacionais. Dentre as vinte e sete UF's existentes em 1991, quatorze delas registraram trocas migratórias positivas no período 1981-1991, destacando-se, além dos Estados do Norte (à exceção do Acre), o saldo positivo do Estado de Sergipe (no Nordeste), do Espírito Santo (no Sudeste) e de Goiás (no Centro-Oeste).

De fato, de uma para outra década, ocorreram significativas mudanças econômicas que tiveram rebatimentos sobre os movimentos migratórios. Ao lado do processo de esgotamento das fronteiras agrícolas, o País conviveu com o importante processo de desconcentração relativa da indústria, que implicou na alteração da distribuição das atividades econômicas, em particular as

\footnotetext{
${ }^{6}$ NEGRI (op. cit.) aponta essa possível defasagem entre dinâmica econômica e dinâmica migratória em seu estudo a respeito do processo de desconcentração da indústria no País.

BRITO, Fausto. "População, espaço e economia numa perspectiva histórica: o caso brasileiro".

8 Brito (ibidem) indica essa tendência para os anos 70.

9 MARTINE, Jorge; CARVALHO, José Alberto M. Cenários demográficos para o século 21 e algumas implicações sociais.

${ }^{10}$ Tocantins ainda fazia parte de Goiás.

11 Eram 15 estados perdedores de população contra 11 ganhadores.
} 
industriais. ${ }^{12}$ Para esse período, pode-se concluir que essa desconcentração relativa da indústria propiciou também fluxos migratórios nessas direções, bem como reteve uma população que potencialmente migraria destas áreas.

Foi particularmente importante no período 1981-1991, o movimento de retorno aos Estados de nascimento, os quais também contribuíram para a elevação no número de Estados ganhadores. Nos anos 70, o movimento de retorno aos Estados de nascimento representava apenas 11,0\% do total da migração nacional, proporção que chegou a dobrar no período 1981-1991, alcançando $24,5 \%$ do total; passou-se de um volume anual de retorno de 105.482 pessoas, no período 1970-1980, para 259.582, entre 1981-1991.

Assim, os anos 80 já indicavam a expansão dos espaços da migração, ${ }^{13}$ tendência que se viu confirmada nos anos 90, particularmente quando se consideram os movimentos intra-regionais e os inter-regionais separadamente.

$\mathrm{Na}$ continuidade das mudanças nos movimentos migratórios, as tendências na migração interna no Brasil nos anos 90 apontaram:

1) os fluxos migratórios de longa distância reduziram-se, consideravelmente, em particular aqueles que se dirigiam às fronteiras agrícolas;

2) mantiveram-se como área de absorção de fluxos de longa distância, os Estados de São Paulo, Rio de Janeiro, Goiás e Distrito Federal, que canalizaram os fluxos do Nordeste;

3) houve a recuperação migratória no âmbito intra-regional de "espaços perdedores" no âmbito nacional, especialmente os Estados nordestinos;

4) houve o surgimento e consolidação de pólos de absorção migratória no âmbito inter-regional e intra-regional, com a maior parte dos Estados tornando-se "ganhadores" de população - mesmo que estes ganhos estejam circunscritos a contextos regionais específicos.

A análise dos movimentos migratórios, em anos recentes - anos 2000, como se procederá a seguir, indica o reforço da tendência de configuração de novos espaços da migração, agora, no entanto, muito mais relacionados ao âmbito de suas próprias regiões.

\section{Cenário recente das Migrações Internas no Brasil}

Quando se considera os movimentos migratórios interestaduais e suas trocas migratórias pode-se verificar entre 1995 e 2009, a manutenção no número de Estados ganhadores de população: 17 Estados entre 1995-2000

12 PACHECO, op. cit.

${ }^{13}$ BAENINGER, Rosana. "A nova configuração urbana no Brasil: desaceleração metropolitana e redistribuição da população". 
e entre 1999-2004. Entre 2001-2006 e 2004-2009, no entanto, foram, respectivamente, 12 e 13 os Estados com ganhos migratórios, refletindo a situação de trocas migratórias negativas dos Estados da Região Norte, as oscilações nas tendências da migração de alguns Estados da Região Nordeste e a nova posição de São Paulo e Rio de Janeiro no cenário de perdas migratórias no contexto das migrações internas no Brasil (Tabela 1).

Ou seja, no início do século XXI, as migrações internas tornaramse ainda mais complexas, sem a definição - que anteriormente poderia se visualizar - dos rumos da migração no país, considerando o comportamento verificado em décadas ou quinquênios anteriores.

\section{TABELA 1}

Volumes de imigração, emigração e trocas migratórias por Regiões e Unidades da Federação Brasil, 1995/2000 e 1999/2004

\begin{tabular}{lcccccc}
\hline \multicolumn{1}{c}{$\begin{array}{c}\text { Regióes e } \\
\text { UFs }\end{array}$} & $\begin{array}{c}\mathbf{1 9 9 5 / 2 0 0 0} \\
\text { I }\end{array}$ & $\begin{array}{c}\mathbf{E} \\
\text { (Imigração) }\end{array}$ & $\begin{array}{c}\text { Trocas } \\
\text { (Emigração) }\end{array}$ & $\begin{array}{c}\mathbf{I} \\
\text { (Imigração) }\end{array}$ & $\begin{array}{c}\mathbf{1 9 9 9 / 2 0 0 4} \\
\text { (Emigração) }\end{array}$ & Trocas \\
Rondônia & 83.325 & 72.734 & 10.591 & 49.046 & 55.239 & -6.193 \\
Acre & 13.635 & 16.069 & -2.434 & 14.777 & 13.212 & 1.565 \\
Amazonas & 89.626 & 58.658 & 30.968 & 64.001 & 52.928 & 11.073 \\
Roraima & 47.750 & 14.380 & 33.370 & 38.384 & 13.325 & 25.059 \\
Pará & 182.045 & 234.213 & -52.168 & 235.111 & 187.426 & 47.685 \\
Amapá & 44.582 & 15.113 & 29.469 & 32.525 & 18.281 & 14.244 \\
Tocantins & 95.430 & 82.513 & 12.917 & 82.312 & 112.004 & -29.69 \\
NORTE & $\mathbf{5 5 6 . 3 9 3}$ & $\mathbf{4 9 3 . 6 8 0}$ & $\mathbf{6 2 . 7 1 3}$ & $\mathbf{5 1 6 . 1 5 6}$ & $\mathbf{4 5 2 . 4 1 5}$ & $\mathbf{6 3 . 7 4 1}$ \\
Maranhão & 100.820 & 274.470 & -173.650 & 180.924 & 258.016 & -77.092 \\
Piauí & 88.736 & 140.815 & -52.079 & 119.646 & 113.952 & 5.694 \\
Ceará & 162.926 & 186.709 & -23.783 & 141.680 & 120.574 & 21.106 \\
Rio G. Norte & 77.917 & 71.286 & 6.631 & 73.494 & 37.284 & 36.210 \\
Paraíba & 102.005 & 163.485 & -61.480 & 138.328 & 95.857 & 42.471 \\
Pernambuco & 164.872 & 280.289 & -115.417 & 179.932 & 204.868 & -24.936 \\
Alagoas & 55.967 & 127.949 & -71.982 & 81.318 & 85.668 & -4.350 \\
Sergipe & 52.109 & 56.921 & -4.812 & 45.843 & 43.258 & 2.585 \\
Bahia & 250.572 & 517.930 & -267.358 & 290.343 & 378.618 & -88.275 \\
NORDESTE & $\mathbf{1 . 0 5 5 . 9 2 4}$ & $\mathbf{1 . 8 1 9 . 8 5 4}$ & $\mathbf{- 7 6 3 . 9 3 0}$ & $\mathbf{1 . 2 5 1 . 5 0 8}$ & $\mathbf{1 . 3 3 8 . 0 9 5}$ & $\mathbf{- 8 6 . 5 8 7}$ \\
Minas Gerais & 447.836 & 408.659 & 39.177 & 429.438 & 398.460 & 30.978 \\
Espírito Santo & 129.169 & 95.149 & 34.020 & 107.132 & 108.669 & -1.537 \\
Rio de Janeiro & 319.749 & 274.223 & 45.526 & 166.036 & 255.653 & -89.617 \\
São Paulo & 1.223 .809 & 884.121 & 339.688 & 823.557 & 978.689 & -155.132
\end{tabular}




\begin{tabular}{lcccccc} 
SUDESTE & $\mathbf{2 . 1 2 0 . 5 6 3}$ & $\mathbf{1 . 6 6 2 . 1 5 2}$ & $\mathbf{4 5 8 . 4 1 1}$ & $\mathbf{1 . 5 2 6 . 1 6 3}$ & $\mathbf{1 . 7 4 1 . 4 7 1}$ & $\mathbf{- 2 1 5 . 3 0 8}$ \\
Paraná & 297.308 & 336.998 & -39.690 & 260.478 & 271.182 & -10.704 \\
Santa Catarina & 199.651 & 139.665 & 59.986 & 214.287 & 139.268 & 75.019 \\
Rio G. do Sul & 113.395 & 152.891 & -39.496 & 116.643 & 146.372 & -29.729 \\
SUL & $\mathbf{6 1 0 . 3 5 4}$ & $\mathbf{6 2 9 . 5 5 4}$ & $\mathbf{- 1 9 . 2 0 0}$ & $\mathbf{5 9 1 . 4 0 8}$ & $\mathbf{5 5 6 . 8 2 2}$ & $\mathbf{3 4 . 5 8 6}$ \\
Mato G. do Sul & 97.709 & 108.738 & -11.029 & 90.071 & 97.271 & -7.200 \\
Mato Grosso & 166.297 & 123.726 & 42.571 & 192.691 & 81.011 & 111.680 \\
Goiás & 372.702 & 169.887 & 202.815 & 315.571 & 168.574 & 146.997 \\
Distrito Federal & 216.200 & 188.551 & 27.649 & 152.073 & 199.982 & -47.909 \\
C-OESTE & $\mathbf{8 5 2 . 9 0 8}$ & $\mathbf{5 9 0 . 9 0 2}$ & $\mathbf{2 6 2 . 0 0 6}$ & $\mathbf{7 5 0 . 4 0 6}$ & $\mathbf{5 4 6 . 8 3 8}$ & $\mathbf{2 0 3 . 5 6 8}$ \\
\hline TOTAL & $\mathbf{5 . 1 9 6 . 1 4 2}$ & $\mathbf{5 . 1 9 6 . 1 4 2}$ & $\mathbf{-}$ & $\mathbf{4 . 6 3 5 . 6 4 1}$ & $\mathbf{4 . 6 3 5 . 6 4 1}$ & - \\
\hline
\end{tabular}

Fonte: Fundação IBGE (2000 y 2004). Tabulação Nepo/Unicamp.

* Não inclui os imigrantes estrangeiros nem os de UF não especificada.

A redefinição da relação migração-industrialização, migração-fronteira agrícola, migração-desconcentração industrial, migração-emprego, migraçãomobilidade social no contexto atual da economia e da reestruturação produtiva, em anos recentes, induziu um novo dinamismo às migrações no Brasil, onde os fluxos mais volumosos são compostos de idas-e-vindas, refluxos, re-emigração, outras etapas - que pode ser mesmo o próprio local de origem antes do próximo refluxo para o último destino -, onde as migrações assumem um caráter mais reversíve ${ }^{14}$ do que nas explicações que nos pautávamos até o final do século XX. Essa reversibilidade diz respeito tanto às áreas de origem, com um crescente vai-e-vem, como às de destino, com o incremento da migração de retorno.

É nesse contexto, que a migração interestadual, para o conjunto do país, continuou exibindo decréscimos em seus volumes: passou de 5,2 milhões, entre 1995-2000, para 4,6 milhões, entre 1999-2004 e de 4,4 milhões, de 2001-2006, para 3,2 milhões entre 2004-2009. Esse decréscimo, contudo, não implica em uma tendência à estagnação das migrações; ao contrário, denota outros arranjos da própria migração interna, bem como seus atuais desdobramentos, com novas modalidades de deslocamentos populacionais em âmbitos locais e regionais.

Para o entendimento deste novo cenário das migrações no país é necessário que se observe as tendências atuais da Região Nordeste. Com uma tendência que se delineia desde os últimos vinte anos, a Região Nordeste continuou o decréscimo em seus saldos migratórios negativos, de 763 mil

${ }^{14}$ DOMENACH, Hervé; PICOUET, Michel. "El caráter de reversibilidad en el estudio de la Migración”. 
pessoas, entre 1995-2000, para 86 mil pessoas, entre 1999-2004, alcançando 53 mil e 168 mil pessoas, respectivamente, entre 2001-2006 e 2003-2008. Entre 2004-2009 o saldo negativo migratório para a região Nordeste mantevese em 187 mil pessoas, o que indica a força da migração de retorno na composição de sua imigração. Esta nova face e nova fase da imigração para o Nordeste estão relacionadas ao contexto atual da Região Metropolitana de São Paulo, em especial, e do Rio de Janeiro, e a reorganização da indústria no território nacional ${ }^{15}$ e internacional ${ }^{16}$.

As dinâmicas migratórias dos Estados do Nordeste são profundamente marcadas por oscilações em termos de recuperação, absorção e expulsão de suas populações que refletem tanto os processos intra-regionais, como a instabilidade das tendências dos movimentos migratórios de retorno. De um lado, o Rio Grande do Norte e o Ceará vêm conseguindo manter trocas migratórias positivas com as demais Unidades da Federação. Do outro lado, o Estado da Bahia é um dos melhores exemplos: com uma trajetória de perdas migratórias por mais de cinquenta anos - apesar do decréscimo em seu volume como um todo - a PNAD 2006 revelou maior contingente de imigrantes (339.133 pessoas) do que de emigrantes (306.116), com um saldo migratório positivo de 33.017 pessoas para esse Estado. No entanto, as PNADs 2008 e 2009 apontam perdas migratórias de 75 mil pessoas e de 108.326, respectivamente, para a Bahia com alta rotatividade migratória. Nesse contexto, torna-se pertinente, mais uma vez destacar, as análises a respeito da reversibilidade das migrações, como aponta Domenach e Picouet. ${ }^{17}$

A compreensão das migrações no Nordeste passa necessariamente pela nova realidade da Região Sudeste. Os movimentos migratórios, do início do século 21, transformaram os grandes Estados de atração populacional dos anos 70 - São Paulo e Rio de Janeiro - em áreas de perdas migratórias. Nas PNADs 2006, 2008 e 2009 é possível identificar que a imigração para São Paulo diminuiu para 765.469 em 2001-2006 para 621.058 entre 2003-2008, chegando a 535.376 migrantes nacionais para o período 20042009 - quando, no período 1995-2000, esta imigração ainda havia sido de 1.223.809 migrantes interestaduais.

Com isso, nas trocas migratórias, o Estado de São Paulo passou de um ganho de migrantes (339.688), no período 1995-2000, para uma perda de -207.098 pessoas, entre 2001-2006, diminuindo esta perda -19.652 pessoas entre 2003-2008 e -53.276 entre 2004-2009. Deve-se ressaltar que estas

\footnotetext{
${ }^{15}$ COUTINHO, Luciano. "Cenários exploratórios do Brasil 2020: comentário".

${ }^{16}$ SASSEN, Saskia. The Mobility of Labor and Capital.

${ }^{17}$ DOMENACH, PICOUET, op. cit.
} 
perdas podem estar relacionadas, muito mais, às saídas de população da Região Metropolitana de São Paulo, com histórico consolidado de migrações interestaduais - em especial nordestina -, do que ao cenário do interior paulista, que vem expandindo suas áreas de migração com o Nordeste mais recentemente. ${ }^{18}$

O Rio de Janeiro teve seu volume de imigrantes diminuído de 319.749, entre 1995-2000, para 210.038, entre 2001-2006, com declínio mais intenso, no período 2003-2008, para 193.793 imigrantes e 141.459 no período 2004-2009, embora com menor força que o decréscimo para São Paulo. Esse estado registrou saldo migratório negativo de -41.596 migrantes, entre 2001-2003, positivo de 12.169 pessoas, no período 2003-2008, voltando a ser negativo entre 2004-2009 (-24.063).

Para as antigas áreas de fronteiras agrícolas, as mudanças nos movimentos migratórios também foram expressivas. Na Região Norte, o início dos anos 2000 aponta a inversão dos processos migratórios em Rondônia. Ainda no período 1995-2000, o Estado registrava trocas migratórias interestaduais positivas (10.591 pessoas), passando para um saldo migratório negativo entre 1999-2004 (-6.193), indicando no período 2001-2006 aumentos em suas perdas migratórias (-20.801 migrantes). Porém, o redesenho dessas áreas com a expansão da "nova fronteira agrícola"19 já se fez sentir nos movimento migratórios do período 2003-2008 com declínio das perdas migratórias, para -6.783, voltando a ter ganhos populacionais entre 2004-2009, em especial Rondônia e Amapá.

Na Região Centro-Oeste, o Mato Grosso do Sul que apresentava tendência de perda de população em 1995-2000 (com saldo negativo de 11.029 migrantes), diminuiu sua emigração, passando a um saldo positivo de 39.818 migrantes, entre 2001-2006. Todavia, no período 2003-2008, esse Estado volta a apresentar trocas migratórias negativa de -5.166 pessoas e oscilando para saldo migratório positivo entre 2004-2009 (7.695 pessoas). Outra tendência inversa no Centro-Oeste é registrada pelo Distrito Federal que de ganhos migratórios, ainda em 1995-2000 (27.649 pessoas), passou para uma perda de população em 2001-2006 de 12.784 pessoas, com maiores volumes negativos no período 2003-2008 (-19.438), mas também voltando a saldos positivos entre 2004-2009 (11.866 pessoas). O Estado do Mato Grosso nos três períodos (1995-2000, 1999-2004 e 2001-2006), apresentou saldo positivo em suas trocas migratórias, porém, no período recente (2003-

\footnotetext{
${ }^{18}$ BAENINGER, Rosana. "Expansão, Redefinição ou Consolidação dos Espaços da Migração em São Paulo? Análises a partir dos primeiros resultados do Censo 2000".

${ }^{19}$ CANO, op. cit.
} 
2008), passou a ter saldo negativo de -16.398 pessoas, com perdas migratórias entre 2004-2009 (-12.027 pessoas). Nota-se, portanto, as tênues fronteiras entre as "condições migratórias" mesmo dos atuais pólos migratórios no país. O importante a reter aqui são os níveis escalares em que se operam tais fenômenos migratórios e sua manifestação local/regional e nacional.

Cabe ainda destacar que, a Região Sul passou a ter saldo positivo no âmbito nacional, de um para outro período: de -19.200, no período 19952000, para 40.534 migrantes, entre 2001-2006, com manutenção do saldo de 40.282 pessoas, no período 2003-2008 e de 98.253 migrantes, entre 2004-2009, em função principalmente dos ganhos migratórios de Santa Catarina.

Considerando-se o Índice de Eficácia Migratória interestadual (IEM), nos períodos 1995-2000, 1999-2004, 2001-2006, 2003-2008 e 2004-2009, nota-se que o país vivencia uma intensa mobilidade da população, com o aumento das áreas de rotatividade migratória, onde o índice de eficácia migratório, tanto positivo quanto negativo, são bastante próximo de zero (Tabela 2). Ou seja, já não há mais áreas de grande retenção migratória e nem de elevada perda migratória. Isto já fica evidente quando observado o comportamento em termos de grandes regiões brasileiras. Para a Região Norte e a Região Sul os índices de eficácia migratória se situam na faixa entre $-0,05$ e 0,14 , ou seja, muito distante dos extremos do indicador (-1 como área de evasão e +1 como área de retenção migratória). Há sim um intenso movimento de rotatividade migratória no Brasil, com o indicador situando-se próximo de zero (entram migrantes e saem migrantes).

Assim, os Estados com índice de eficácia próximo ao de rotatividade migratória - mesmo com valores negativos (entre -0,12 e 0,12) - são no período 2004-2009: Rondônia, Acre, Amazonas, Maranhão, Ceará, Paraíba, Pernambuco, Sergipe, Minas Gerais, Rio de Janeiro, São Paulo, Paraná, Mato Grosso do Sul, Mato Grosso, Rio Grande do Sul e Distrito Federal, compreendendo dezessete estados brasileiros.

Os Estados com capacidade de retenção migratória (IEM acima de 0,12, com valor superior de 0,30), no período 2004-2009 totalizam apenas 5 estados: Amazonas, Rio Grande do Norte, Espírito Santo, Santa Catarina e Goiás. Já as áreas de perdas migratórias (IEM entre -0,12 e -0,30) são apenas: Pará, Tocantins, Piauí, Alagoas, Bahia. Destaca-se que essas áreas têm apresentado também oscilações em suas "condições migratórias" como demonstra a evolução do IEM. 
TABELA 2

Índice de eficácia migratória por Regiões e Unidades da Federação Brasil, 1995-2010

\begin{tabular}{|c|c|c|c|c|c|c|}
\hline UFs & $1995 / 2000$ & $1999 / 2004$ & 2001/2006 & $2003 / 2008$ & $2004 / 2009$ & $2005 / 2010$ \\
\hline Rondônia & 0,07 & $-0,06$ & $-0,22$ & $-0,08$ & 0,03 & 0,10 \\
\hline Acre & $-0,08$ & 0,06 & 0,15 & 0,17 & 0,01 & $-0,03$ \\
\hline Amazonas & 0,21 & 0,09 & $-0,03$ & 0,09 & 0,28 & 0,16 \\
\hline Roraima & 0,54 & 0,48 & 0,68 & 0,36 & 0,02 & 0,39 \\
\hline Pará & $-0,13$ & 0,11 & 0,06 & 0,01 & $-0,15$ & $-0,11$ \\
\hline Amapá & 0,49 & 0,28 & $-0,05$ & $-0,36$ & 0,29 & 0,42 \\
\hline Tocantins & 0,07 & $-0,15$ & $-0,14$ & $-0,04$ & $-0,24$ & 0,05 \\
\hline NORTE & 0,06 & 0,07 & 0,01 & $-0,01$ & $-0,05$ & 0,04 \\
\hline Maranhão & $-0,46$ & $-0,18$ & $-0,18$ & $-0,21$ & $-0,11$ & $-0,44$ \\
\hline Piauí & $-0,23$ & 0,02 & $-0,05$ & $-0,03$ & $-0,17$ & $-0,32$ \\
\hline Ceará & $-0,07$ & 0,08 & 0,12 & 0,06 & $-0,02$ & $-0,23$ \\
\hline Rio G. Norte & 0,04 & 0,33 & 0,22 & 0,13 & 0,24 & 0,11 \\
\hline Paraíba & $-0,23$ & 0,18 & $-0,1$ & $-0,21$ & 0,02 & $-0,13$ \\
\hline Pernambuco & $-0,26$ & $-0,06$ & $-0,03$ & $-0,04$ & $-0,03$ & $-0,20$ \\
\hline Alagoas & $-0,39$ & $-0,03$ & $-0,2$ & $-0,36$ & $-0,30$ & $-0,42$ \\
\hline Sergipe & $-0,04$ & 0,03 & $-0,08$ & 0,15 & 0,02 & 0,08 \\
\hline Bahia & $-0,35$ & $-0,13$ & 0,05 & $-0,15$ & $-0,21$ & $-0,34$ \\
\hline NORDESTE & $-0,27$ & $-0,03$ & $-0,02$ & $-0,09$ & $-0,10$ & $-0,27$ \\
\hline Minas Gerais & 0,05 & 0,04 & 0,05 & 0,1 & 0,02 & $-0,02$ \\
\hline E. Santo & 0,15 & $-0,01$ & 0,25 & 0,18 & 0,33 & 0,30 \\
\hline Rio Janeiro & 0,08 & $-0,21$ & $-0,09$ & 0,03 & $-0,08$ & 0,04 \\
\hline São Paulo & 0,16 & $-0,09$ & $-0,12$ & $-0,02$ & $-0,05$ & 0,15 \\
\hline SUDESTE & 0,12 & $-0,07$ & $-0,05$ & 0,03 & $-0,01$ & 0,10 \\
\hline Paraná & $-0,06$ & $-0,02$ & $-0,02$ & 0,03 & 0,08 & $-0,04$ \\
\hline S. Catarina & 0,18 & 0,21 & 0,26 & 0,3 & 0,26 & 0,40 \\
\hline Rio G. Sul & $-0,15$ & $-0,11$ & $-0,17$ & $-0,23$ & $-0,07$ & $-0,27$ \\
\hline SUL & $-0,02$ & 0,03 & 0,04 & 0,05 & 0,11 & 0,06 \\
\hline Mato G. Sul & $-0,05$ & $-0,04$ & 0,2 & $-0,04$ & 0,07 & 0,10 \\
\hline Mato Grosso & 0,15 & 0,41 & 0,25 & $-0,08$ & $-0,07$ & 0,08 \\
\hline Goiás & 0,37 & 0,3 & 0,18 & 0,25 & 0,32 & 0,40 \\
\hline D. Federal & 0,07 & $-0,14$ & $-0,04$ & $-0,09$ & 0,04 & 0,04 \\
\hline C. OESTE & 0,18 & 0,16 & 0,13 & 0,06 & 0,14 & 0,20 \\
\hline TOTAL & 5.196 .142 & 4.635 .641 & 4.463 .418 & 3.327 .741 & 3.240 .083 & 4.643 .752 \\
\hline
\end{tabular}

Fonte: Fundação IBGE, Censo Demográfico de 2000 e 2010, e PNAD 2004, 2006, 2008 e 2009. 
O entendimento das migrações internas atuais, a partir desse novo olhar para os processos migratórios, conduz à substituição de conceitos historicamente datados, tais como: a) áreas de evasão por áreas de perdas migratórias; b) áreas de atração ou absorção por áreas de retenção migratória; c) áreas de origem e destino por áreas/etapas constituintes dos processos de rotatividade migratória.

Duas dimensões estão particularmente presentes na re-definição desses processos: em primeiro lugar, a própria reversibilidade ${ }^{20}$ dos diferentes fluxos migratórios, em especial as oscilações nos volumes de emigração e imigração e suas novas modalidades. Em segundo lugar, a menor permanência das condições da migração para a caracterização das áreas.

Os volumes dos fluxos migratórios interestaduais para o período 20002010, segundo o Censo Demográfico de 2010, totalizaram 11.409.086 pessoas que declararam ter mudado de Unidade da Federação na década e confirmando as grandes tendências que se delinearam com as informações das PNADs, em especial quando se observa os índices de eficácia migratória. O que mais chama a atenção é o fato do Censo 2010 não ter comprovado a perda migratória do Estado de São Paulo, como as PNADs da década vinham apontando (com Índice de Eficácia Migratória em torno de -0,05 pelas PNADs e de 0,15 com o Censo). Porém o censo continua a confirmar a tendência de rotatividade migratória do Estado de São Paulo, como pudemos captar com as PNADs.

Considerando as trocas migratórias nas últimas duas décadas (Tabelas 3a e 3b) para todas as Unidades da Federação do país, é possível verificar os menores patamares da migração interestadual, com a Região Norte tendo decrescido seu saldo migratório de 245.998 pessoas entre 1970-1980 para 146.962 entre 2000-2010. A região Nordeste diminuiu sua perda migratória, mantendo em torno de -1,6 milhões suas trocas migratórias entre 1990-2000 e 2000-2010. A Região Sul revelou no período 2000-2010 perdas migratórias para o Rio Grande do Sul e Paraná. O Centro-Oeste manteve seus elevados ganhos populacionais, em torno de 600 mil pessoas.

Destaca-se, no período 2000-2010, a Região Sudeste com troca migratória em torno de 800 mil pessoas, quando no período 1990-2000 havia sido de 1,8 milhão. Essa diminuição nos ganhos migratórios do Sudeste se deveu à forte redução na imigração para São Paulo: de 3.254.389 imigrantes entre 1990-2000 para 2.507.631 entre 2000-2010, tendo a emigração registrado: 1.789 .544 e 1.840 .193 , respectivamente. Com isso

${ }^{20}$ DOMENACH, PICOUET, op. cit. 
as trocas migratórias de São Paulo com as demais Unidades da Federação passaram de 1.464.846, entre 1990-2000, para 667.438 pessoas no período 2000-2010.

TABELA 3a

\section{Volumes de Imigração e Emigração Interestaduais* e Trocas Migratórias} Brasil, 2000-2010

\begin{tabular}{|c|c|c|c|c|}
\hline \multirow[b]{2}{*}{ Regiões e UFs } & \multicolumn{4}{|c|}{ BRASIL } \\
\hline & Imigração & Emigração & $\begin{array}{c}\text { Trocas } \\
\text { migratórias }\end{array}$ & IEM \\
\hline Norte & 1.147 .743 & 1.000 .781 & 146.962 & 0,07 \\
\hline Nordeste & 2.381 .889 & 4.080 .204 & -1.698 .315 & $-0,26$ \\
\hline Sudeste & 4.410 .181 & 3.597 .042 & 813.139 & 0,10 \\
\hline Sul & 1.559 .832 & 1.450 .774 & 109.058 & 0,04 \\
\hline C. Oeste & 1.907 .431 & 1.278 .275 & 629.156 & 0,20 \\
\hline \multicolumn{5}{|c|}{11.407 .076} \\
\hline Rondônia & 152.914 & 136.367 & 16.547 & 0,06 \\
\hline Acre & 33.501 & 34.377 & -876 & $-0,01$ \\
\hline Amazonas & 171.151 & 122.441 & 48.710 & 0,17 \\
\hline Roraima & 62.078 & 25.601 & 36.477 & 0,42 \\
\hline Pará & 451.988 & 460.689 & -8.701 & $-0,01$ \\
\hline Amapá & 85.690 & 36.882 & 48.808 & 0,40 \\
\hline Tocantins & 190.421 & 184.424 & 5.997 & 0,02 \\
\hline Maranhão & 268.487 & 677.350 & -408.863 & $-0,43$ \\
\hline Piauí & 173.776 & 351.306 & -177.530 & $-0,34$ \\
\hline Ceará & 309.027 & 452.275 & -143.248 & $-0,19$ \\
\hline R.G.Norte & 161.443 & 140.981 & 20.462 & 0,07 \\
\hline Paraíba & 223.337 & 324.489 & -101.152 & $-0,18$ \\
\hline Pernambuco & 370.987 & 588.262 & -217.275 & $-0,23$ \\
\hline Alagoas & 143.703 & 307.060 & -163.357 & $-0,36$ \\
\hline Sergipe & 121.924 & 118.966 & 2.958 & 0,01 \\
\hline Bahia & 609.205 & 1.119 .515 & -510.310 & $-0,30$ \\
\hline M. Gerais & 914.847 & 986.045 & -71.198 & $-0,04$ \\
\hline E. Santo & 286.428 & 185.623 & 100.805 & 0,21 \\
\hline Rio Janeiro & 701.275 & 585.180 & 116.095 & 0,09 \\
\hline São Paulo & 2.507 .631 & 1.840 .193 & 667.438 & 0,15 \\
\hline Paraná & 649.067 & 738.089 & -89.022 & $-0,06$ \\
\hline S. Catarina & 618.129 & 328.653 & 289.476 & 0,31 \\
\hline Rio G. do Sul & 292.636 & 384.031 & -91.395 & $-0,14$ \\
\hline Mato G. Sul & 227.334 & 197.269 & 30.065 & 0,07 \\
\hline Mato Grosso & 386.904 & 359.182 & 27.722 & 0,04 \\
\hline Goiás & 817.939 & 393.761 & 424.178 & 0,35 \\
\hline D. Federal & 475.254 & 428.063 & 47.191 & 0,05 \\
\hline
\end{tabular}

* Não inclui sem especificação (2.012 casos).

Fonte: FIBGE, Censo Demográfico de 2000 e 2010. 


\section{TABELA 3b}

\section{Volumes de Imigração e Emigração Interestaduais* e Trocas Migratórias São Paulo, 2000-2010}

\begin{tabular}{l|c|c|c|c}
\hline Regiões e UFs & $\begin{array}{c}\text { Imigração para } \\
\text { São Paulo }\end{array}$ & $\begin{array}{c}\text { Emigração de } \\
\text { São Paulo }\end{array}$ & $\begin{array}{c}\text { Trocas } \\
\text { Migratórias São } \\
\text { Paulo }\end{array}$ & IEM São Paulo \\
\hline Norte & 59.150 & 52.839 & 6.311 & 0,06 \\
\hline Nordeste & 1.451 .666 & 701.672 & 749.994 & 0,35 \\
\hline Sudeste & 547.442 & 490.669 & 56.773 & 0,05 \\
\hline Sul & 301.913 & 388.899 & -86.986 & $-0,13$ \\
\hline C. Oeste & 147.460 & 206.114 & -58.654 & $-0,17$ \\
\hline \multicolumn{1}{c|}{ TOTAL } & $\mathbf{2 . 5 0 7 . 6 3 1}$ & $\mathbf{1 . 8 4 0 . 1 9 3}$ & $\mathbf{6 6 7 . 4 3 8}$ & $\mathbf{0 , 1 4}$ \\
\hline Rondônia & 11.267 & 13.903 & -2.636 & $-0,10$ \\
\hline Acre & 1.538 & 2.014 & -476 & $-0,13$ \\
\hline Amazonas & 8.732 & 7.115 & 1.617 & 0,10 \\
\hline Roraima & 1.020 & 1.452 & -432 & $-0,17$ \\
\hline Pará & 27.661 & 17.672 & 9.989 & 0,22 \\
\hline Amapá & 1.357 & 1.195 & 162 & 0,06 \\
\hline Tocantins & 7.576 & 9.488 & -1.912 & $-0,11$ \\
\hline Maranhão & 92.114 & 25.948 & 66.166 & 0,56 \\
\hline Piauí & 126.882 & 44.066 & 82.816 & 0,48 \\
\hline Ceará & 155.121 & 93.004 & 62.117 & 0,25 \\
\hline R.G.Norte & 31.320 & 33.736 & -2.416 & $-0,04$ \\
\hline Paraíba & 99.043 & 57.599 & 41.444 & 0,26 \\
\hline Pernambuco & 244.174 & 124.557 & 119.617 & 0,32 \\
\hline Alagoas & 122.895 & 47.042 & 75.853 & 0,45 \\
\hline Sergipe & 38.157 & 25.717 & 12.440 & 0,19 \\
\hline Bahia & 541.959 & 250.002 & 291.957 & 0,37 \\
\hline M. Gerais & 418.348 & 366.699 & 51.649 & 0,07 \\
\hline E. Santo & 18.352 & 22.562 & -4.210 & $-0,10$ \\
\hline Rio Janeiro & 110.742 & 101.408 & 9.334 & 0,04 \\
\hline São Paulo & & & & $-0,09$ \\
\hline Paraná & 225.541 & 271.796 & -46.255 & $-0,34$ \\
\hline S. Catarina & 38.682 & 79.158 & -40.476 & 0,00 \\
\hline Rio G. do Sul & 37.690 & 37.946 & -256 & $-0,16$ \\
\hline Mato G. Sul & 55.822 & 77.723 & -21.901 & $-0,13$ \\
\hline Mato Grosso & 31.976 & 41.829 & -9.853 & \\
\hline & & & \\
\hline & 2.012 & & & \\
\hline
\end{tabular}

* não inclui sem especificação (2.012 casos).

Fonte: FIBGE, Censo Demográfico de 2000 e 2010.

O caso de Estado de São Paulo, portanto, é indicativo da complexidade que assume o fenômeno migratório no século 21. Tendo sido considerado o pólo nacional das migrações no Brasil por mais de 50 anos, caracteriza-se por distintas "condições migratórias" a depender dos fluxos que se processam de e com São Paulo. Nas principais trocas migratórias ocorridas entre 2000-2010, dentre os estados brasileiros, São Paulo apresentou-se como área de forte 
perda migratória para Santa Catarina e estados do Centro-Oeste; com a Região Norte, apresenta saldos migratórios negativos com estados como Rondônia, Acre, Roraima, Amapá, mas ganha migrantes do Pará. Com os estados do Nordeste voltou a reter população do Maranhão, Piauí, Pernambuco, Ceará e Bahia, mesmo que em menores patamares que em décadas anteriores. Já com os demais estados brasileiros São Paulo caracteriza-se como área de rotatividade migratória.

Como se poderia visualizar essa configuração migratória para São Paulo dez anos atrás? Como mantermos a hipótese de que esta tendência atual de rotatividade migratória permanecerá? A passagem de uma "condição migratória" de retenção, perda ou rotatividade migratória para as áreas requer o entendimento da complexidade que o fenômeno migratório assumiu no século 21, pela generalização do processo de urbanização, pelas modalidades migratórias e pelos reflexos da inserção na dinâmica global.

Nesse contexto de redefinição de áreas de retenção e perdas migratórias, redesenha-se a mobilidade espacial da população no Brasil, com processos migratórios que resultam na expansão dos espaços de rotatividade migratória. A tendência de menores saldos migratórios para o Sudeste, evidenciada já entre $1999-2004,{ }^{21}$ revela a consolidação dos espaços da migração no país, onde a complementaridade migratória, historicamente existente entre Nordeste-Sudeste, se redefine num cenário de menores fluxos migratórios, com decréscimo na absorção migratória e a presença da rotatividade migratória. Não se trata, contudo, apenas das "duplas migratórias" - como define Wendin ${ }^{22}$ para as migrações internacionais - mas sim de variados sentidos e direção das migrações internas no Brasil.

Pode-se caracterizar os espaços da migração no Brasil na última década da seguinte maneira:

- área de retenção migratória nacional e regional, ou seja, o novo pólo das migrações, o Estado de Goiás, situado na região CentroOeste e área de expansão da nova fronteira agropecuária

- áreas de retenção migratória regional, estados do Mato Grosso (Região Centro-Oeste), Pará (Região Norte), Rio Grande do Norte (Região Nordeste), Espírito Santo (Região Sudeste) e Santa Catarina (Região Sul);

${ }^{21}$ CUNHA, José Marcos P. "A migração no Brasil no começo do Século 21: continuidades e novidades trazidas pela PNAD 2004"; HAKKERT, Ralph e MARTINE, George. "Tendências migratórias recentes no Brasil: as evidências da PNAD de 2004"; BRITO, CARVALHO, op. cit.

22 WENDEN, Catherine. "Un essai de typologie des nouvelles mobilités". 
- área de rotatividade migratória nacional: São Paulo e Rio de Janeiro, em especial suas metrópoles

É nesse sentido, que se pode observar nas migrações internas do Brasil, na primeira década do século 21, uma faixa que se estende do Mato Grosso passando por Goiás, Tocantins, Maranhão e Piauí até o Pará (áreas dos commodities exportáveis, fronteira mineral e agropecuária). Já no Norte/ Nordeste do país, as novas áreas de expansão da fronteira agrícola ganham importância na recepção dos fluxos migratórios do Pará com a atual retenção migratória de Roraima, espelhando, portanto, processos locais da esfera global. Já o outro corredor da migração nacional é historicamente conformado pelos fluxos Nordeste-Sudeste, e agora pelos seus refluxos Sudeste-Nordeste, onde transitam os volumes mais elevados da migração do país, com intensas áreas de rotatividade migratória. Reconfiguram-se espacialidades migratórias em âmbito sub-regional, como são os casos de Minas Gerais, Bahia e São Paulo.

Nesse contexto de redefinição de áreas de retenção e perdas migratórias, redesenha-se a mobilidade espacial da população no Brasil, com processos migratórios que resultam na expansão dos espaços de rotatividade migratória. A tendência de perda migratória do Sudeste revela a consolidação dos espaços da migração no país, onde a complementaridade migratória historicamente existente entre Nordeste-Sudeste - se redefine num cenário de rotatividade migratória.

Desse modo, o cenário migratório do século 21 apresenta dois grandes vetores redistributivos nacionais. O primeiro é caracterizado pela "dispersão migratória metropolitana", que em nível nacional é marcado pelos significativos volumes de migrantes de retorno interestaduais que partem do Sudeste em direção ao Nordeste. No âmbito intra-estadual, esta tendência se evidencia com a conformação de importantes fluxos migratórios metrópoleinterior.

Nesse sentido, o segundo vetor refere-se a "interiorização migratória", com trajetórias migratórias de mais curtas distâncias, envolvendo aglomerações urbanas e espaços não-metropolitanos, expressos na maior retenção de população migrante nos estados e nas regiões. A reversibilidade dos processos migratórios adquire significado distinto quando se contempla dinâmicas urbano-regionais específicas.

As migrações no século 21 redefinem seus pólos, configurando mais áreas de retenção da migração do que áreas com uma tendência polarizadora de longa permanência, como foi o caso do Sudeste nos últimos cinquenta 
anos. Essas modificações são resultados de inúmeras transformações ocorridas no cenário econômico internacional e nacional, que trouxeram efeitos em termos políticos e econômicos. Tais mudanças exercem efeitos sobre a decisão de migrar, e num contexto mais atual, sobre a decisão de permanecer ou não na Região/Estado para a qual migrou em tempos passado.

Entretanto, os volumes de imigração e emigração entre NordesteSão Paulo não deverão ser muito menores. Em um contexto de enormes transformações na dinâmica produtiva, onde o setor terciário tem importante papel - quer seja nas metrópoles do Sudeste ou do Nordeste - e o emprego na indústria oscila conforme o mercado internacional, a rotatividade migratória tenderá a se consolidar, marcando uma nova fase do processo de redistribuição espacial da população brasileira.

\section{Rotatividade Migratória: conceito para as migrações urbanas no século 21}

O fenômeno migratório atual apresenta especificidades que indicam tanto sua complexidade, advinda do processo de reestruturação urbana e econômica, quanto seu importante papel na conformação de espaços regionais e locais. O entendimento do fenômeno como processo históricosocial, como já indicava Singer ${ }^{23}$, constitui a raiz do entendimento também para os processos migratórios urbanos atuais.

As localidades de partida e chegada, contudo, não se configuram mais como as antigas áreas de origem e destino conforme pensadas para a migração rural-urbana desde suas formulações clássicas. ${ }^{24} \mathrm{O}$ expressivo retorno migratório revela configurações da migração e de trajetórias urbanas-urbanas não contempladas nos conceitos datados em seu tempo histórico.

Poder-se-ia, então, recorrer ao conceito de circulação para as análises dos processos migratórios atuais?

Zelinsky ${ }^{25}$ define circulação como uma etapa de transição para movimentos migratórios permanentes, diferenciando circulação de migração, uma vez que a primeira não implica em mudança de residência e com restrita temporalidade. Nesta mesma direção, Chapman, Muray e Prothero ${ }^{26}$ denominam circulação como um conceito que substitui migração, quando não há mudança permanente de residência.

\footnotetext{
${ }^{23}$ SINGER, Paul. "Migrações internas: considerações teóricas sobre o seu estudo".

${ }^{24}$ Ibidem; LEE, Everett S. "Uma teoria sobre a migração".

${ }^{25}$ ZELINSKY, Wilbur. "The hypothesis of the mobility transition".

${ }^{26}$ CHAPMAN, Murray; PROTHERO, Mansell. "Themes on circulation in the Third World".
} 
Skeldon ${ }^{27}$ destaca

(...) the process of wage labor circulation must refer to many interrelated macro factors - land inequality, pauperization, uprooting, rural exodus, conditions maintaining both rural and urban poverty, disarticulation of links between village and town, spatial-economic disorganization, urban polarization of resources, the parasitic character of urban areas and possibly many more. Collectively these may be called the working of a syndrome of poverty and mobility. Wage labour circulation is just one manifestation of this syndrome.

Essas interpretações conceituais, portanto, ainda estão baseadas em um excedente populacional na origem rural que circula por trabalhos sazonais ou temporários no lugar de destino. Ainda na perspectiva das migrações ruraisurbanas, a circulação traduziria a complementaridade dos deslocamentos de população; tais conceitos partem de uma sociedade em transição para o mundo urbano, onde as mudanças na estrutura agrária geram um contingente de "força de trabalho móvel". ${ }^{28}$

A circulação, em sua formulação clássica, traduz a força de trabalho disponível em meio às transformações geradas pelo urbano e pela industrialização. Considera-se, contudo, que este conceito de circularidade, na etapa atual da sociedade urbanizada encontra limites para contemplar a complexidade do fenômeno migratório, uma vez que se baseia em áreas de origem menos dinâmicas para áreas de destino com dinâmicas produtivas e capacidade em emprego, mesmo que temporários ou sazonais. O olhar é para o destino migratório.

O conceito de rotatividade migratória contempla, por sua vez, como primeiro pressuposto, tratar-se de um fenômeno migratório eminentemente urbano e que - também no âmbito das migrações internas - constitui um fato social total. ${ }^{29}$ Ou seja, a imigração e a emigração fazem parte de um mesmo processo social, sendo um fenômeno que comporta transformações na esfera social, na dimensão econômica e cultural no local de partida e de chegada; Sayad $^{30}$ se refere ao conceito de double absence para o entendimento das migrações internacionais nessa perspectiva.

A segunda premissa do conceito de rotatividade migratória vincula-se à expansão clássica do capitalismo com a circulação de capital, mercadorias e

\footnotetext{
${ }^{27}$ SKELDON, Ronald. Population Mobility in Developing Countries, p. 293.

${ }^{28}$ SPAAN, Ernst. Labour circulation and socioeconomic transformation. The case of East Java, Indonesia.

${ }^{29}$ SAYAD, Abdelmalek. La Double absence: dês ilusions de l'emigré aux soufrances de l’immigré.

${ }^{30}$ Ibidem.
} 
pessoas, construindo um excedente populacional. No contexto atual, esse é um excedente populacional urbano gerado tanto na área de origem como na área de destino, que será rotativo dependendo das necessidades do capital e da inserção dessas localidades na divisão social e territorial do trabalho em âmbito nacional e internacional. A rotatividade da mão de obra nos processos migratórios - via rotatividade migratória - contribuirá para atender as demandas e custo da força de trabalho nos locais de chegada e de partida.

A releitura do conceito de força de trabalho móvel pode ser contemplada como uma dimensão das migrações internas urbanas da atualidade. No contexto atual da reestruturação da economia em nível internacional e seus rebatimentos em âmbitos locais ${ }^{31}$ a força de trabalho móvel urbana tende a crescer, em especial em uma economia baseada nos serviços, com a fluidez também dos movimentos migratórios no atual processo de urbanização.

O conceito de rotatividade migratória pressupõe ainda a dimensão espacial para o entendimento dos processos migratórios ${ }^{32} \mathrm{e}$, mais que isto, seus espaços de vida, ${ }^{33}$ com idas-e-vindas, retornos, temporalidades limitadas.

Nesse sentido, as explicações das dinâmicas migratórias internas no país têm se aproximado cada vez mais de aportes teóricos acerca das migrações internacionais, quer seja na vertente do tema das redes sociais, ${ }^{34}$ quer seja na vertente da demanda por trabalhadores, como indicado por Krissman ${ }^{35}$.

É no espaço de vida, ${ }^{36}$ no campo social ${ }^{37}$ onde agentes "ocupam posições relativas em um espaço de relações que, ainda que invisível e sempre difícil de expressar empiricamente, é a realidade mais real (...) e o princípio real dos comportamentos dos indivíduos e dos grupos", constituindo os espaços sociais da migração.

\section{Considerações finais}

As evidências empíricas acerca das migrações internas no Brasil conduzem a novos olhares para a interpretação dos movimentos migratórios e sua descrição, bem como impõe enorme desafios conceituais.

\footnotetext{
31 HARVEY, Daniel. Condição Pós-Moderna.

32 VILLA, Miguel; RODRIGUEZ, Jorge. "Dinámica sociodemografica de las metrópolis latinoamericanas".

${ }^{33}$ COURGEAU Daniel. Méthodes de Mesure de la Mobilité Spaciale: migration internes, mobilité temporaire, navettes.

${ }^{34}$ MASSEY, Douglas et alii. Worlds in motion: understanding International Migration at the end of the millennium.

${ }^{35}$ KRISSMAN, Fred. "Sin coyote ni patrón: why the 'Migrant Network' fails to explain International Migration".

${ }^{36}$ COURGEAU, op. cit.

37 BOURDIEU, Pierre. "Efeitos do lugar".
} 
Em termos empíricos, o elemento que mais chama a atenção se refere à complementaridade migratória - como transferências de população do Nordeste para o Sudeste -, que parecia ter diminuído nos anos 80, volta a ser retomada nos 90, porém se redesenha nos 2000. O Nordeste registrava um total de 1,3 milhão de emigrantes para outras regiões, em 1986-1991, elevando-se para 1,8 milhão em 1995-2000; a partir dos anos 2000 diminui para o patamar de 1,3 mil emigrantes no período 2001-2006, e para 980 mil emigrantes entre 2003-2008, mas voltando a um milhão entre 2004-2009. Essas oscilações nos volumes da imigração e emigração entre o Nordeste e Sudeste parecem confirmar as enormes idas-e-vindas, o caráter reversibilidade dos movimentos migratórios internos de longa distância no Brasil.

As migrações no século 21 redefinem seus pólos, configurando mais áreas de retenção da migração do que áreas com uma tendência polarizadora de longa permanência, como foi o caso do Sudeste nos últimos cinquenta anos. Essas modificações são resultados de inúmeras transformações ocorridas no cenário econômico internacional e nacional, que trouxeram efeitos em termos políticos e econômicos. Tais mudanças exercem efeitos sobre a decisão de migrar, e num contexto mais atual, sobre a decisão de permanecer ou não na Região/Estado para a qual migrou em tempos passado.

Entretanto, os volumes de imigração e emigração entre NordesteSão Paulo não deverão ser muito menores. Em um contexto de enormes transformações na dinâmica produtiva, onde o setor terciário tem importante papel - quer seja nas metrópoles do Sudeste ou do Nordeste - e o emprego na indústria oscila conforme o mercado internacional, a rotatividade migratória tenderá a se consolidar, marcando uma nova fase do processo de redistribuição espacial da população brasileira.

Nesse contexto, torna-se cada vez mais evidente a complexidade do entendimento das migrações internas na sociedade brasileira do século 21. Encontrar caminhos teórico-metodológicos para a nova leitura das migrações internas no Brasil requer considerar que para a conceitualização de rotatividade migratória torna-se importante destacar que estamos diante de uma nova sociedade: reflexiva ${ }^{38}$, de risco ${ }^{39}$, da tecnologia da informação ${ }^{40}$. Assim, no caso da compreensão de espaços de "partida e chegada" tão difusos é imprescindível considerar a articulação de processos locais ao âmbito regional e global, que promovem "mecanismos de desencaixe" da

\footnotetext{
${ }^{38}$ GIDDENS, Anthony. As Consequências da Modernidade.

39 BECK, Ulrich. Risk Society: Towards a new modernity.

${ }^{40}$ CASTELLS, Manuel. A Sociedade em Rede.
} 
sociedade,$^{41}$ com reflexos nos processos de urbanização e de redistribuição espacial da população nos variados contextos regionais.

Por sua vez, as novas territorialidades e os espaços da migração aceleram seu processo de emergência na sociedade de riscos. Nesta, os riscos são compartilhados ${ }^{42} \mathrm{e}$, portanto, a rotatividade migratória - marcada por entradas e saídas - está imersa em um conjunto de "sistemas peritos" da sociedade ${ }^{43}$ : desde a facilidade de transportes até a conformação de novos espaços da migração no âmbito local e regional. A intensificação de áreas com rotatividade migratória no país indica a fluidez da força de trabalho em espaços compartilhados da sociedade de risco. Esse parece ser um caminho promissor para o aprofundamento das interpretações acerca do fenômeno migratório na contemporaneidade, bem como para o processo de configuração de espaços regionais.

\section{Bibliografia}

BAENINGER, Rosana. "A nova configuração urbana no Brasil: desaceleração metropolitana e redistribuição da população", in Anais do XI Encontro nacional de Estudos Populacionais. Caxambu: ABEP, 1998.

. "Expansão, Redefinição ou Consolidação dos Espaços da Migração em São Paulo? Análises a partir dos primeiros resultados do Censo 2000", in Anais do XIII Encontro Nacional de Estudos Populacionais. Ouro Preto: ABEP, 2002.

. Região, Metrópole e Interior: espaços ganhadores e espaços perdedores nas migrações internas no Brasil, 1980-1996. Tese de Doutorado. Campinas: IFCHUNICAMP, 1999.

BECK, Ulrich. Risk Society: Towards a new modernity. London: Sage Publications, 1992. BOURDIEU, Pierre. "Efeitos do lugar", in BOURDIEU, Pierre (coord.). A miséria do mundo. Petrópolis: Vozes, 1997.

BRANDÃO, C. A. Território e desenvolvimento: as múltiplas escalas entre o local e o global. Campinas: Editora da UNICAMP, 2007.

BRITO, Fausto. População, espaço e economia numa perspectiva histórica: o caso brasileiro. Tese de Doutorado, Faculdade de Ciências Econômicas, CEDEPLAR/ UFMG, 1997.

BRITO, Fusto; CARVALHO, José A. "As migrações internas no Brasil: as novidades sugeridas pelos Censos Demográficos de 1991 e 2000 e pelas PNADs recentes", in Parcerias Estratégicas, n. 22, 2006, p. 441-454.

\footnotetext{
${ }^{41}$ GIDDENS, op. cit.

${ }^{42}$ OJIMA, Ricardo. Instituições políticas e Mudança Ambiental: os novos arranjos institucionais na gestão de recursos hídricos e suas interfaces políticas.

${ }^{43}$ GIDDENS, op. cit.
} 
CANO, Wilson. "Novas Determinações sobre a Questão Regional e Urbana após 1980". Texto para Discussão n. 193. Instituto de Economia/UNICAMP, julho de 2011.

CASTELLS, Manuel. A Sociedade em Rede. Rio de Janeiro: Paz e Terra, 1999.

CHAPMAN, Murray; PROTHERO, Mansell. "Themes on circulation in the Third World", in Circulation in Third World countries. Londres: Routledge \& Kegan Paul, p. 1-26, 1985.

COURGEAU, Daniel. Méthodes de Mesure de la Mobilité Spaciale: migration internes, mobilité temporaire, navettes. Paris: L'Institut National D’Estudes Démographiques, 1988.

. "Nuevos enfoques para medir la movilidad espacial interna de la población", in Notas de Población, Santiago de Chile, CELADE, n. 50, 1990.

COUTINHO, Luciano. "Cenários exploratórios do Brasil 2020: comentário", in Revista ANPEC, n. 4, p. 43-46, 1998.

CUNHA, José Marcos P. "A migração no Brasil no começo do Século 21: continuidades e novidades trazidas pela PNAD 2004", in Parcerias Estratégicas, n. 22, p. 381-439, 2006

CUNHA, José Marcos; BAENINGER, Rosana. "Cenários da migração no Brasil nos anos 90", Cadernos do CRH, vol. 18, núm. 43, pp.87-101.2005.

DOMENACH, Hervé; PICOUET, Michel. "El caráter de reversibilidad en el estudio de la Migración", in Notas de Población, n. 49, 1990.

DINIZ, Célio C. "Dinâmica regional recente e suas perspectivas", in AFFONSO, Rui de Britto A.; SILVA, Pedro Luiz B (orgs.). A federação em perspectiva: ensaios selecionados. São Paulo: Fundap, 1995, p. 417-429.

FARIA, Vilmar. "Cinquenta anos de urbanização no Brasil: tendências e perspectivas", in Novos Estudos CEBRAP, n. 29, p. 98-119, 1991.

HAKKERT, Ralph; MARTINE, George. "Tendências migratórias recentes no Brasil: as evidências da PNAD de 2004", in Parcerias Estratégicas, n. 22, p. 347-379, 2006.

GIDDENS, Anthony. As Consequências da Modernidade. São Paulo: Editora UNESP, 1991.

HARVEY, David. A Condição Pós-Moderna. São Paulo: Editora Loyola, 1992.

KRISSMAN, Fred. "Sin coyote ni patrón: why the "Migrant Network" fails to explain International Migration", in International Migration Review, v. 39, n. 1, p. 4-44, 2005.

LATTES, Alfredo E. "Population distribution in Latin America: is there a trend towards population deconcentration?", in UNITED NATIONS. Population, distribution and migration. New York, 1998.

LEE, Everett S. "Uma teoria sobre a migração", in MOURA, Hélio (org.). Migração interna: textos selecionados. Fortaleza: Banco do Nordeste do Brasil S.A., 1980.

MARTINE, George. "A evolução espacial da população brasileira", in AFFONSO, Rui de Britto A.; SILVA, Pedro Luiz B. (orgs.). Desigualdades regionais e desenvolvimento. São Paulo: FUNDAP/Ed. UNESP, 1995, p. 61-91. 
- "A redistribuição espacial da população brasileira durante a década de 80". Textos para Discussão, n. 329, Brasília, 1994.

. "Migração e metropolização", in Revista São Paulo em Perspectiva, v. 1, n. 2, 1987, p. 28-31.

MARTINE, George; CARVALHO, José Alberto M. Cenários demográficos para o século 21 e algumas implicações sociais. Campinas: Editora da UNICAMP, 1989.

MARTINE, George; CAMARGO, Líscio. "Crescimento e distribuição da população brasileira: tendências recentes", in Revista Brasileira de Estudos de População, v. 1, n. 2, 1984, p. 99-143.

MASSEY, Douglas; ARANGO, Joaquin; HUGO, Graeme; KOUAOUCl, Ali; PELLEGRINO, Adela; TAYLOR, James. Worlds in motion: understanding International Migration at the end of the millennium. Oxford: Oxford University Press, 1998.

NEGRI, Barjas. Concentração e desconcentração industrial em São Paulo (1880-1990). Campinas: Editora da UNICAMP, 1986.

OJIMA, Ricardo. Instituições políticas e Mudança Ambiental: os novos arranjos institucionais na gestão de recursos hídricos e suas interfaces políticas. Dissertação de Mestrado, Campinas: UNICAMP, 2003.

PACHECO, Carlos Américo. Fragmentação da nação. Campinas: IE/UNICAMP, 1988. SAYAD, Abdelmalek. La Double absence: dês ilusions de l'emigré aux soufrances de I’immigré. Paris: Seul, 1999.

SINGER, Paul. "Migrações internas: considerações teóricas sobre o seu estudo", in Economia política da urbanização. São Paulo: Editora Brasiliense/CEBRAP, 1973, p. 29-60.

SKELDON, Ronald. Population Mobility in Developing Countries. London; New York: Bedhaven Press, 1990.

SPAAN, Ernst. Labour circulation and socioeconomic transformation. The case of East Java, Indonesia. The Hague: NIDI, Report n. 56, 1999.

SASSEN, Saskia. The Mobility of Labor and Capital. Cambridge University Press, 1988. VILLA, Miguel; RODRIGUEZ, Jorge. “Dinámica sociodemografica de las metrópolis latinoamericanas", in Documentos Docentes, Santiago de Chile, 1994.

WENDEN, Catherine. "Un essai de typologie des nouvelles mobilités", in Hommes \& migration, n. 1233, 2001.

ZELINSKY, Wilbur. "The hypothesis of the mobility transition", in Geographical Review, v. 61, n. 2,1971 , p. 219-249. 


\section{Abstract}

\section{Migratory turnover: a new look at internal migration in Brazil}

This article analyses the migration movements in Brazil, following the changes in their dynamics in recent decades. The movements of internal migration in Brazil, the last 60 years, are strongly related to the processes of urbanization and spatial redistribution of population, both marked by intense population mobility. In this context, classical factors of attraction and expulsion run out of explanations for migration. Empirical evidences of demographic censuses and "National Survey by Household Samples" (PNADs) make it possible to know the changes in national migration trends, revealing new conditions of migration for different states: areas of migratory retention, areas of migratory losses and areas of migratory turnover. The 21st century announces the expansion of migration spaces in Brazil, marked by the growth of areas of migratory turnover.

Keywords: Internal migration; Urbanization; Interstate migration.

Recebido para publicação em 04/10/2012.

Aceito para publicação em 15/11/2012.

Received for publication in October, 04, 2012.

Accepted for publication in November, 15 ${ }^{\text {th }}, 2012$. 